\title{
Ethics vs. Economics: The Issue of Free Trade with Mexico
}

ABSTRACT. The authors, one an ethicist and the other an economist, look at the issue of free trade with Mexico and other low wage rate countries from the viewpoints of their disciplines. The conclusion of the paper is that these disciplines differ on their priorities and analytical methods, not on their objectives.

\section{Ethics vs. economics: the issue of free trade with Mexico}

Free trade with Mexico has recently become the subject of an important, and emotional, public policy debate in the United States. The issue is not so much the duty-free exchange of goods and services between the two countries, given the comparative advantages of each. The issue is the nature of the comparative advantage in Mexico: the existence of very low wage rates which leads to the transfer of manufacturing operations and jobs from the United States to Mexico.

Very low wage rates are an economic reality

LaRue Tone Hosmer is professor of Corporate Strategy and Managerial Ethics at the Graduate School of Business Administration of the University of Michigan. He is the author of Moral Leadership in Business (Irvin, 1993), The Ethics of Management, 2nd Edition (Irwin, 1991), and Strategic Management (PrenticeHall, 1984).

Scott E. Masten is associate professor of Business Economics and Public Policy at the Graduate School of Business Administration of the University of Michigan. His work has appeared in the American Economic Review, the Journal of Institutional and Theoretical Economics, and the Journal of Law, Economics, and Organization. in all of the non-industrialized countries of Central and South America. Indeed, it must be understood that Mexico is used in the current debate as a symbol of a potentially much wider concern: the transfer of manufacturing operations and jobs from the United States to low wage rate areas throughout the Western Hemisphere. This transfer obviously creates economic hardships within the affected communities in the United States, and equally obviously produces economic benefits in the regions of the 3rd World countries where the factories are built.

The question is whether this transfer of U.S. manufacturing operations, which creates hardships in one area and benefits in another, is "right" and "just" and "fair". Two academic disciplines deal with questions expressed in those moral terms of rightness, justice, and fairness: normative philosophy though the principles of ethical analysis and neoclassical economics through the concepts of welfare equilibrium.

One of us is an ethicist and the other an economist. We intend in this article, to apply those principles and those concepts generally to the debate over free trade with Central and South America, but more specifically to the arguments about the benefits and harms of the Mexican maquiladoras. The Mexican maquiladoras presently exist. Their operations have been studied. Their positive and negative outcomes are known and can be cited, unlike the much hazier potential impacts of future free trade agreements with other low wage rate countries.

\section{The Mexican maquiladoras}

Maquiladoras are manufacturing plants located in 
Mexico that process goods and services destined for the U.S. market. The goods tend to be high volume industrial components and consumer goods that require minimal job skills such as auto parts, textile items, and electronic units. The services tend to be high volume information processing tasks that also require minimal job skills, primarily in data entry. Most of the maquiladoras are owned by U.S. firms. They have been located in Mexico to take advantage of the low wage rates that are prevalent in that country.

The wage rates in Mexico are low in comparison to the United States, and that difference is particularly noticeable in the maquiladora plants which usually are located in areas with a large labor supply but a limited worker demand. In 1990, the last year for which comparative data are available, the average wage paid to manufacturing employees in the United States was $\$ 10.84$ per hour. In Mexico the equivalent figure was $\$ 1.55,{ }^{1}$ while in the maquiladoras it was just two thirds of that amount, at $\$ 0.99 .^{2}$ In some of the maquiladoras located in southcentral Mexico wages as low as $\$ 0.63$ have been reported. ${ }^{3}$ Allegedly as a result of the wage rates, which are obviously low by Mexican standards, the maquiladora workforce is not representative of the population. $80 \%$ of the workers in the maquiladora factories are women, and another $10 \%$ are children between the ages of 12 and $16 .^{4}$

The term "maquiladora" originally referred to the toll a flour mill would charge for grinding the grain that belonged to farmers and land owners. The new industrial plants in Mexico operate on much the same basis. They do not own the products they produce. Instead, they receive under bond the sheet metal for auto parts or the cotton and synthetic fibers for textile items or the electronic components for television sets and recording units from their parent firms in the U.S. They process the auto parts and textile items or assemble the television sets and recording units, and then ship back the completed products. Import duties back to the U.S. for the completed products are charged only on the value added by the low wage rate labor, and consequently do little to raise the overall costs of the goods. With the advent of free trade, of course, both the need for the export bonds and the payment of the import duties by the U.S. firms will be eliminated.

The maquiladora industry has expanded rapidly since its formation in 1970 . The concept allegedly started as an agreement between the two countries to provide more factory jobs in Mexico and thus lessen the illegal immigration into the United States. By 1990 there were 1886 maquiladora plants operating in Mexico, and they employed more than 500000 workers. Originally most of these plants had been built along the border to reduce freight costs, but by 1990 they had expanded far into the interior. It is estimated that the number of maquiladora plants and their workers will easily double over the next five years, and triple if the free trade agreement with Mexico becomes a reality. ${ }^{5}$

\section{Benefits of the maquiladoras}

As an ethicist and as an economist we agree generally on the benefits that accrue to both Mexico and the United States as a result of the present maquiladora program and the proposed free trade agreement. We may disagree on the exact size and relative timing of those benefits, but we do agree that they exist:

Mexican employment. The first benefit is also the most obvious one and doubtless the most critical one for the Mexican economy. Maquiladoras provide 500,000 jobs in a country that historically has suffered from very low industrialization and very high unemployment. $17 \%$ of all the manufacturing jobs in Mexico are now said to be at American owned maquiladora plants. ${ }^{6}$ The wage rates are admittedly low, even by Mexican standards, but the work requires only rudimentary job skills and most plants - except for those in the poverty-stricken south central portion of the country - pay about $20 \%$ higher than the Mexican minimum wage.

Mexican development. The maquiladora plants perform for the most part very low level fabrication and assembly operations, but they perform them using mass manufacturing technologies under strict controls for both quality and cost. 
Exposure to those technologies, and experience with those controls, is certainly an important step in the development of the Mexican economy. In addition, some of the employees are being trained as maintenance personnel and others for low level supervision which, again, is a necessary first step for further industrialization.

American competitiveness. The maquiladoras provide low cost manufacturing capabilities to American firms, and thereby help to counter the current Japanese move to combine their capital, technology, and skilled assembly at home with low cost component manufacturing throughout southeastern Asia. European firms, particularly in Germany, will soon have access to the low cost component manufacturing capabilities of Eastern Europe. It is certainly possible to argue that without equivalent access to low skilled and low cost labor in Mexico, the global competitiveness of North American firms will eventually be distinctly diminished.

American markets. Lastly, the maquiladora plants provide paying jobs and raise living standards in Mexico, a nation of ninety million consumers who eventually should come to demand U.S. exports in both products and services. The annual per capita income in Mexico, which now stands at only $\$ 2250$, is admittedly much too low to support active import markets in automobiles, appliances and other "big ticket" items, but again it is certainly possible to argue that the increased Mexican prosperity will eventually lead to expanded American exports of consumer goods, industrial equipment, and financial services.

\section{Harms of the maquiladoras}

As an ethicist and as an economist we also agree generally on the harms that have come to both Mexico and the United States as a result of the present maquiladora program and the future free trade agreement. We may disagree on the exact size and personal impact of those harms, but we do agree that they exist:

American unemployment. Each new job created in Mexico by an American-owned maquiladora plant results in the loss of the equivalent job in the United States. That job might have been lost regardless of the Mexican transfer by a lack of American competitiveness, and it may be replaced in the near future by an expansion of the Mexican market for imported goods and services, but the unemployment in North America does create a hardship for the individual workers and the affected communities.

Unsafe working conditions. The American owners of the maquiladora factories are, of course, not required to meet U.S. standards for workplace safety. The are required to meet Mexican standards, but those rules and regulations are much less stringent and they tend to be poorly enforced. Few maquiladora plants are open to inspection by independent researchers, and consequently the degree of workplace safety cannot be verified. It has to be assumed that most of the plants meet reasonable safety standards, but it also has to be admitted that numerous reports have criticized the textile factories for "chronic asthma, conjunctivitis, bronchitis and brown lung as common occupational diseases" caused by cotton dust and air-borne fibers, and the protection of workers in some electronic, firm processing, and woodworking maquiladoras against toxic chemicals and hazardous materials is said to be "extremely poor"?

Unhealthful environmental discharges. As with worker safety, the American owners of the maquiladora factories are not required to meet U.S. standards for the protection of the environment. Once again, few maquiladora plants are open to inspection by independent researchers, but solid waste dumps and liquid waste discharges can be observed from outside the property line. Numerous environmentalists have criticized the maquiladoras on the grounds that they have severely polluted the border regions. High levels of copper, selenium, mercury, and various hydrocarbons have been found in the rivers, while large dumps of plastic, metal, rubber, paint, resin, and packing materials waste are found on land near the new industrial parks. Under a binational agreement, the maquiladoras are 
required to ship hazardous chemicals back to the United States for proper treatment and disposal following notification of the EPA. But, the proper treatment and disposal of hazardous chemical waste is very expensive, and this binational agreement seems to be widely ignored. In 1989 the EPA reported just 12 notifications of the required shipments back to the United States. $^{8}$

The question we want to address is whether this mixture of benefits and harms is "right" and "just" and "fair." Should public policies within the United States and Mexico encourage or discourage or attempt to ameliorate the impacts of further use by American firms of the low cost labor in the Mexican maquiladoras? It this practice beneficial or harmful to the welfare of the two societies? We will start with the view of the ethicist.

\section{Basic position of the ethicist}

The issue is not whether the benefits of this action - the transfer of manufacturing operations from the United States to Mexico - outweigh the harms. That would be simple Utilitarianism (Mill): ${ }^{9}$ always select the action with the greatest net social benefit. Utilitarianism is the principle that is so often roughly translated as "the greatest good for the greatest number."

There are two problems with the "greatest good" principle. Both are well known and generally accepted. The first is that it is difficult to measure many of the non-economic benefits an harms. How do we measure the harms to the Mexican workers through the toxic working conditions, for example, when we know that many industrial health problems do not surface for years after the initial exposure? How do we measure the harms to the Mexican environment through the proliferation of solid waste dumps, as another example, with their constant threats to the ground water supplies in that arid country? Unfortunately, the normal tendency is to simply ignore those hard-to-measure harms, particularly if they are in another country far from our purview and concern.

The second problem with Utilitarianism is that the distribution of the benefits and harms is also ignored; only that net social balance is felt to be important. Obviously, that is inappropriate. If we could show substantial benefits for the American companies, and substantial though somewhat smaller harms for the Mexican workers and residents, for example, few people would then argue that the resulting balance was "right" and "just" and "fair." Most would simply agree that this was another example of economic colonialism.

Distribution does matter. Distribution is also the topic of one of the most compelling of the ethical principles: Distributive Justice (Rawls). ${ }^{10}$ The basic concept is that the members of society who cooperate for the production of social goods are not indifferent to the distribution of those goods; they would obviously prefer to have more rather than less. Numerous alternative methods have been devised to govern that distribution: to each person according to his or her ability, effort, position, need, or existence. Our present society makes use of all five methods, but all are to some extent unjust because all, again to some extent, disregard the legitimate claims of others.

According to the proponent of the principle of Distributive Justice, the one agreement that people would make if they were ignorant of their future ability, energy, position, or need relative to others would be that the least among us those with the least ability, energy, or position or those with the most need - should not be harmed but instead should be included in the distribution. The amount of that distribution is not specified; instead the rule is that this group should receive some of the benefits from every action. This, it is felt by most ethicists, has to be the most "just" proposal for the distribution of social goods because it has to be the most disinterested: people at the time they made this social contract would not know whether they would benefit or suffer from the agreement because they would be ignorant of their relative position.

Now we come to the issue of the maquiladoras and the transfer of manufacturing operations. Who suffers? The least amongst us: those with least income, least education, least influence, least ability to look after their own self-interests, on both sides of the border. Unskilled workers in 
the United States lose their jobs. Unskilled workers in Mexico are hired in their place, but at wages that are not attractive in any market sense or the workforce would not be so overwhelmingly young and female. The Mexican workers bear the brunt of the unsafe working conditions and the harmful environmental discharges, as well. Clearly the present operations of the maquiladora factories are "unjust." They do not meet the tenets of Distributive Justice.

\section{Basic position of the economist}

The axiom of Distributive Justice described above is an improbable ethical precept. First, measurement difficulties plague theories of Distributive Justice exactly as they do Utilitarianism. By what measure do we determine who is least amongst us? If based on ability, energy, position or need, how do we assess these characteristics and how do we choose among or weight these criteria? It a person with a slow metabolism and $\$ 10000$ better or worse off than an energetic person with $\$ 5000$ ? Do mental, physical, or financial capabilities have a greater influence on well being? Measurement issues pervade all theories of ethical behavior concerned with the impact of actions on the welfare of individuals.

A more important criticism of the rule that each action not harm the least amongst us, however, is that individuals behind the Veil of Ignorance are unlikely to choose a society that required the least amongst them to benefit from "every action." Consider, for example, a series of actions, the end result of which was an enormous improvement in the lot of the poorest individuals but some proper subset of which would result in small and transitory losses to those individuals. To say that individuals behind the Veil of Ignorance would rule out such actions is to say that individuals would never save today to increase their consumption tomorrow because saving and investment necessarily reduce wellbeing today.

More general, most people (all but those that are infinitely averse to risk) would be willing to give up some degree of equality in outcomes in order to gain a measure of progress. It is hard to imagine preferences under which individuals (again, unaware of their prospective position in society) would favor a society that impoverishes the bulk of its members in the name of equity over a society that tolerates some inequality of wealth but provides a respectable standard of living for the vast majority of its citizens. One could claim that such a tradeoff between equity and wealth does not exist. Unfortunately, the evidence does not support that assertion.

But even if such a strong form of the principle of Distributive Justice were accepted, the maquiladora system would withstand ethical scrutiny. Since the economic and social status of Mexicans employed by the maquiladoras in obviously so much lower than their counterparts in the U.S., there are only two ways maquiladora operations can be held to violate the ethical imperative not to harm the least amongst us. The first is to define "amongst us" so narrowly as to exclude Mexican workers, a position so patently chauvinistic it demands no further comment. The other is to argue that the existence of maquiladoras somehow actually makes Mexicans worse off.

The employees of the maquiladoras certainly do not perceive themselves as worse off, as evidenced by the large number of Mexicans attracted to these jobs. The immediate benefit is gainful employment for a young and unskilled work force. Employment in the maquiladoras, moreover, provides workers with experience and cultivates basic work skills essential for their future advancement. Clearly, then, the maquiladoras improve the lot of their Mexican employees and thus satisfy even the overly restrictive standard associated with the notion of Distributive Justice you describe.

\section{First response of the ethicist}

Obviously measurement problems are present in Distributive Justice, but the measurements here do not need to be as precise as in the consequential theories. All we need do is identify the least amongst us, and we can readily do that in ways that are satisfactory to an ethicist if not to 
an economist. They are the people with the least money, the least education, the least ability to influence the decisions and actions that affect themselves, and we can find them on both sides of most national borders. The U.S. workers who have been left without jobs may or may not be worse off than the Mexican workers who appear to be underpaid. That is not the issue. The issue is that we should not harm either group, and yet that is precisely what is happening.

Before going on to discuss those harms, and their lack of remedy through the imperfect labor markets, let me stress that Distributive Justice does not mean that the participants in the Social Contract are unable somehow to compute the net present value of a series of actions, or to recognize the income stream associated with savings and investments and delayed consumption. Further, the principle does not mean that everyone must have equal income or similar wealth or equivalent education. It does mean, however, that those with income and wealth and education should not harm those without. A simple and, to my mind, decent ethical prescription.

If you are going to avoid that simple and decent ethical prescription, then you will have to claim that the U.S. workers who are left without jobs they may have held for years have not been harmed, and that the Mexican workers who are so poorly paid that the maquiladora workforce is admittedly skewed towards the young and the female, also have not been harmed. In short, you will have to appeal to the supposed impartiality of the labor markets in both countries.

If the labor force in the affected communities in the U.S. was truly mobile - that is, if the displaced workers could easily move geographically to a different community or technically to a different industry - and if the national economy in the United States was adequately prosperous - that is, if the displaced workers could quickly find a range of different opportunities from which to choose - then we could safely disregard the harms to those people. But, those conditions - which are essential assumptions of economic theory - are seldom if ever met.

The same conditions - the lack of a labor market that is truly mobile and a national economy that is truly prosperous - exist with even greater force in the rural sections of Mexico where the maquiladora factories are located. The problems are compounded there because the bargaining power relationship between the single dominant employer and the numerous potential employees is so obviously unequal. We can see the results: low wages, long hours, poor conditions. Labor markets require an equivalency of position, an ability to say "no." When that ability to say "no" is removed, the supposed connection between the market for labor and the welfare of society is also removed.

The critical importance of the ability to say "no" is derived from another ethical principle: Contributive Liberty (Nozick). ${ }^{11}$ The central concept here is that liberty is more important than justice, and that consequently the one agreement that people would make who were ignorant of their future ability, energy, or position would be that no one should ever interfere with the rights of others for self-development and self-fulfillment. We don't have to guarantee the rights of others to develop to the fullest of their abilities; we just don't want to interfere with those rights. Yet, that is precisely what is happening.

Workers in both the United States and Mexico have clearly been denied the rights to selfdevelopment and self-fulfillment through the lack of mobile and efficient markets for their labor. The workers in Mexico are further denied those rights to self-development and self-fulfillment through the imposition of harms to their health in the poor working conditions and the severe environmental damages. I do hope that you at least briefly mention the working conditions and environmental damages in your next statement.

\section{First response of the economist}

I do not want to belabor the measurement issue but, suffice it to say, the requirements of Distributive Justice are no less in measurement respects than those of economic theories and thus do not provide dispositive grounds to favor the former over the latter. ${ }^{12}$ On the conceptual level, meanwhile, I am pleased to see that you have 
made a major concession regarding the application of the "least-amongst-us" rule. Specifically, your acknowledgement of the appropriateness of assessing "the net present value of a series of actions" admits (i) the possibility of conflicts between short-run and long-run effects of actions, and (ii) that individual actions cannot be evaluated in isolation from the broader complex of social and economic interactions. This is important because the existence of tradeoffs between immediate and ultimate consequences of particular ethical rules implies the need to assess and compare the harms with the benefits, that is, to make cost-benefit analyses.

Consider some of the implications of Distributive Justice as you define it. All progress, every advance in history, has involved dislocations. The advent of air travel displaced workers in the railroad industry, the development of which had previously displaced barge labor. Mass production of automobiles had similar consequences for blacksmiths. If new research revealed the potential for an unlimited source of safe and inexpensive energy, would it be unethical to develop the technology because coal miners and oil and gas field hands would lose their livelihoods? Under such a rule, it would be an unethical God that sent manna from heaven, thereby destroying the livelihood of farmers. Strict application would also enjoin minimum wages, each $10 \%$ increase in which reduces employment of teenagers and young adults (the least skilled and lowest paid) by $1 \%$ to $2 \%$, as well as many occupational and environmental regulations that also displace workers and inhibit new job creation. Ironically, whereas each action described above would fail a strict interpretation of the least-amongst-us rule, a social welfare criterion requires only a showing of sufficient net benefits.

The maquiladoras raise precisely the same issues. The world is imperfect, and progress in this as in any other area inevitably causes dislocations. The question is whether overall the world will be a better place if we permit the free flow of resources across international borders or prohibit it. Ask the Mexican workers whether they consider themselves better off with or without the maquiladoras. Unsuccessful and obviously frustrated union organizers have complained of maquiladoras, "Unfortunately, their workers are very happy". ${ }^{13}$ I have already cited the basic skills and work experience these workers receive, which must ultimately enhance their employability and self-worth. The best way to expand those opportunities and to enhance the economic position of Mexican workers is to foster, not inhibit, investment in new businesses south of the border.

Regarding work and environmental conditions, it is true that Mexican laws are more lenient toward work-place hazards and pollution than our own. One needs to recognize, however, that, like food, running water, refrigeration, and medical care, a more pleasant work environment is costly. While each item on this list contributes to a better quality of life, given finite resources, the cost of an additional peso spent improving the environment is one less peso available for food, housing, rudimentary medical care, and other basics. More stringent regulation of businesses also risks discouraging investment and slowing the development of the Mexican economy. It should not be surprising then, in light of its level of economic development, that Mexico and other countries in its position adopt less severe environmental standards. As incomes increase, both the total and relative shares of resources that populations are willing to allot to various purposes change. We have a responsibility perhaps to share our knowledge about the nature of the tradeoffs involved and to foster representative political institutions, but a policy that forces another society to adopt the standards that we, in our relative affluence, find congenial is both condescending and injurious to the welfare of the Mexican poor.

Last, if not least, is the effects of the maquiladoras on Americans. The most conspicuous harms are, of course, to dislocated workers, and no one should minimize the trauma losing one's job can cause. But we must also consider the effects of maquiladora operations on other Americans. Far worse off than the average American factory worker are many people who have never benefitted from such jobs in the first place, who don't have the remedial work skills and discipline needed to hold a steady job, who 
are physically or mentally impaired, or who must raise children without a spouse. Because restrictions on the movement of resources inevitably raise prices and because poor individuals must expend a much larger fraction of their income on consumption, the burden of such price increases fall disproportionately on the poor. Trade restrictions, especially on food, clothing, transportation, and other basic commodities; are, in effect, a regressive tax. Furthermore, limitations on the ability of entrepreneurs to eliminate or transfer jobs will ineluctably discourage the creation of new jobs. The harm caused to individuals whose opportunities to find gainful employment are circumscribed is just as real as that suffered by those whose jobs are displaced. Again, we are forced to apply cost-benefit reasoning: Would the benefits of restricting trade to the subset of American workers harmed by the free flow of resources exceed the combined costs to Mexican workers, American consumers, and the millions of American workers who benefit from international trade.

Surely it is a dubious ethical principle that would deny to some of the world's poorest people access to American markets and, with that, the relative prosperity that a system of free markets and free enterprise has bestowed on Americans. Indeed facilitating trade among countries is probably the single most important thing we can do to relieve economic hardship and suffering throughout the world. If you disagree, perhaps you could be specific about what sort of system you think would lead to an ethically superior outcome.

\section{Second response of the ethicist}

Before I accept your challenge to describe the "sort of system that would lead to an ethically superior outcome", let me take up one or two other issues that you have recently raised. Firstly, it seems obvious to me that there is a massive difference between employment dislocations caused by technological advances such as those you cite - air travel replaced the railroads which in turn had replaced barge traffic - and those caused by job exports. Technological advance occur slowly. Employees have time to adjust. Job exports occur quickly, with termination notices handed out on Friday afternoons. Technological advances create new opportunities that are immediate, apparent, and often are local. Job exports create new opportunities that may occur at some future time, in some unrelated industry, in some distant community. One group apparently has to "take the hit" in all major economic change. Why does that "hit" always seem to be ignored or smoothed over or assumed away in economic theory? Why does that group always seem to include those people who have the least resources - both financial and psychological - for waiting, retraining, and moving in response to the change? Both responses go against simple concepts of justice.

Let me also say just a word or two about your proposal that Mexican citizens should be able to make their own trade-offs between employment opportunities, workplace hazards, and environmental damages. Of course they should! We agree totally. But, there have to be choices. One offer of an employment opportunity contingent upon certain workplace hazards and environmental harms is not a choice. It is a ultimatum. Externally imposed ultimatums go against simple concepts of liberty.

Now, we come to the decision system that should lead to ethically superior outcomes. I think that I have been describing exactly that sort of system in this discussion. It has to include the concept of justice. It has to include the concept of liberty. It has to include the concept of duty. And, lastly, it has to include a smattering of compassion.

You don't like my definition of justice (Rawls), but you suggest none to take its place beyond what $I$ assume is a reliance upon what seem to me to be obviously flawed factor and product markets, and a laudable though hazy intent to compute the external costs imposed upon people. I think that we as a society have to be much more exact than that in thinking about such an important concept as justice. What exactly do you mean by the term? Where precisely does justice fit in economic theory?

You don't like my definition of liberty (Nozick) either, but again you suggest none to 
take its place beyond what I assume is the same reliance upon flawed product and factor markets and the intent, again laudable but hazy, to "foster representative political institutions". Here also as a society I think that we have to be much more careful in thinking about such as important concept. What exactly are the rights of the workers in the United States whose jobs have been transferred to Mexico? What exactly are the rights of the workers in Mexico who are forced to work at wages that we would not accept in the United States - even given the differences in the living standards - under workplace conditions and environmental damages we would not permit in the United States. Where do the rights of individuals fit in economic theory, or are they simply neglected and ignored?

I have not yet provided a definition of duty. One of the central tenets of normative ethics is that if we have rights we also have duties. What do we owe to others? The answer of the ethicist is that the only duty we truly owe to others is that of consistency in our actions, that similar situations should be addressed similarly regardless of momentary changes in our self interests. This is the ethical principle, also very compelling in my view, of Universal duties (Kant), ${ }^{14}$ expressed in the two formulations of the Categorical Imperative.

This first formulation of the Categorical Imperative is that we should take no action that we are not willing to have become a universal law, incumbent upon ourselves as well as others. That is, if we subject workers in the lower skill positions in our society to a continual auction worldwide for their jobs - who is willing to do this task equally well but more cheaply? - then we have the duty to subject workers in the higher skill positions - including ourselves, our friends and our colleagues - to an equivalent auction. We tend not to do that, and we cite differences in training requirements, certification exams, tenure policies, personal relationships, and legal restrictions as the reasons, but according to Kant we have a duty to be consistent, and to understand that if it is "right" in one instance it must be "right" in the other.

The same argument obviously applied to issues of workplace safety and environmental pollution.
If we adopt one set of standards on those issues in the United States, then we have a duty to extend those same standards to our operations in Mexico. It does not matter that the Mexicans are perhaps more desperate for jobs, and willing to accept lower and much more harmful standards; we have a duty to treat everyone, regardless of their social or economic or political positions, exactly alike.

The second formulation of the Categorical Imperative is derived from the first formulation; it states that we should treat others as ends in themselves, worthy of dignity and respect, not as means to our ends. The managers of the companies that own the maquiladora factories obviously treat the displaced workers in the United States and the underpaid workers in Mexico as means to corporate goals, and clearly violate that rule.

The second formulation of the Categorical Imperative is compassion; it is also expressed in all of the world's major religions. It is not as exact as the other three principles - do not harm the least amongst us; do not interfere with an individual's right to self-development; and do not take any action that you are unwilling to have become a universal duty, applicable to all - but it is still important. The lack of precision is the reason I said I wanted a "smattering" of compassion in the system. That term will give you all sorts of opportunities to complain about the imprecision of measurements in ethics.

In short, to answer your question, I want an economic system for the production of goods and services in which there is an explicit definition of justice, of rights, and of duties, together with a general acceptance or recognition or "smattering" of compassion. Economic theory in its present state neglects all four of those critically important concepts. Consequently $\mathbb{I}$ think that it is the wrong theoretical structure to use when evaluating major public policy changes such as the proposed free trade agreement with low wage countries in Central and South America that will cause such obvious harms to so many members of society in all of the countries. 


\section{Second response of the economist}

I do not know where you got the idea that economists ignore the harms caused by economic change. After reviewing what I have written above, I am certain that I have said nothing to warrant that opinion. On the contrary, my entire focus has been on the best way to improve the lot of the least advantaged in society. There is, moreover, an extensive literature in economics on justice, duties, rights, and even altruism. The idealized notion of product and factor markets you disparage represents a convenient straw man but an inaccurate characterization of the state of economic analysis.

The more important message, however, is that understanding economics is a prerequisite to developing sound ethical prescriptions. Employing rudimentary economic principles, I have sought to establish two points: first, that your "explicit definition" of justice, strictly interpreted, implies behavior that is incompatible with ethical intuitions, and second, that any ethical rule that does conform to widely held ethical intuitions must be congruent with cost-benefit reasoning. Your own arguments belie your denials. Your defense, for instance, that the pace of change associated with technological innovation differentiates it from other economic transformations - aside from the disputable factual accuracy of that claim - reveals that the standard you embrace is relative, not absolute: Harms to the least amongst us are in the end justifiable, you admit, as long as the harms are not too severe or persistent and the benefits sufficiently large and immediate.

If the validity of ethical rules does indeed turn on their consequences, then we have an obligation to discover the consequences of proposed rules in their entirety. Not the least among economics' contributions to moral philosophy is the apparatus to analyze the complex of interactions among individuals in society and to trace the effects of particular rules on those individuals well being. As I indicated earlier, good if misplaced intentions to help one set of individuals often result in other individuals, less fortunate still, being harmed. It does not help the cause of justice to ignore harms caused by our actions simply because their causal relations are more complicated or subtle, especially if the tools already exist to identify and measure those consequences. Understanding economics may not be a sufficient condition for deriving ethical principles, but it is arguably a necessary one.

Finally, real, sustained advancement in the living standards of the world's poor requires concrete, pragmatic policies and institutions. Sure, the world would be a better place if individuals behaved ethically. If people could be trusted not to lie or cheat in their business dealings, enormous resources could be saved on lawyers if nothing else. But the desirability of compelling by force of law those who would not otherwise conform their behavior to ethical norms is a separate question from what the norms of individual behavior should be. $I$, as an individual, may be moved by compassion or a sense of duty to pay my workers more than the market requires. In effect, I pay for the satisfaction I receive from improving their situation or simply from behaving virtuously, and no one suffers from my action. (Although even virtue has a price! Am I more virtuous distributing my finite wealth to my employees or to impoverished villagers in southern Mexico - or might it not be better still to reinvest my earnings in productive assets that create new jobs and increase, rather than merely redistribute, the economic pie?) But laws mandating "ethical" behavior requiring, for instance, that employers compensate workers at above market rates - may actually have deleterious ethical implications, as the documented effects of minimum wage legislation on the employment of the lowest-skilled workers illustrates. Like minimum wage laws, legal impediments to trade with Mexico, however well intentioned, cannot bring about real, sustained improvements in the condition of the least among us,

In the end, it is not enough to say that you favor an economic system founded on justice, liberty, and duties. You must also explain how the values you espouse translate into practical results. Through what means do you propose to increase the living standards of the Mexican masses if not by promoting investment in the Mexican economy? How do you plan to insulate 
the poor in our own country from the higher prices that would result from prohibiting the flow of resources to lowest producers? It is no longer a matter of conjecture, one need only look at the world around us to see that economies based on property rights, free markets, and democratic political institutions do the most to enhance the freedom and living standards of their citizens. Granted, there is room for improvement. But every proposed adjustment will involve tradeoffs, gains and losses exactly like the ones we have been discussing here. ${ }^{15}$ As yet, no one has developed a better system, though assorted utopians have amply earned their appellation trying.

\section{Conclusion of the ethicist}

You have a legitimate issue in the complexity of economic interactions, and you state your position very well. But, I do not agree with your belief that "the validity of ethical rules turns upon (the) consequences" of those economic interactions. There are some decisions and actions that are simply wrong, regardless of their consequences. There are the ones that contradict the basic ethical principles of justice, of rights, and of duties, and the basic ethical prescription of compassion.

It would appear that the difference between us is one of priority, not of objective. I believe that a conceptual framework to guide public policy decisions and actions that stresses justice, rights, duties, and compassion and that assumes adequate output of material goods and services will best serve society. You apparently believe that a conceptual framework that stresses efficient production of goods and services, and that assumes adequate conditions of justice, rights, duties, and compassion, will best serve society. Given the increasing cost competition of the global economy, and the expanding importance of public decisions on such issues as trade policies, living standards, working conditions, and environmental limits, we shall soon determine empirically which of us is correct.
Conclusion of the economist

Certainly, ends do not justify means. At the same time, however, no one would accept as a universal ethical principle a rule that would have monstrous consequences. And monstrous indeed are the conditions many of the world' poor must endure. Much of the world's misery is beyond anyone's power to remedy; if we have any ethical obligations at all, surely they must include taking steps to relieve those conditions where some measure of relief is within our power to give. If you and I can agree on that, the remaining question is whether free trade serves or frustrates that purpose. On that we obviously disagree.

In the end, we cannot base public policies or business decisions on theories that assume either an adequate level of goods and services or an adequate condition of justice, rights, and duties. The two are inextricably intertwined. The sooner that notion becomes broadly accepted, the sooner the norms of prosperity and equity will be advanced.

\section{Notes}

1 Yearbook of Labour Statistics, International Labor Office, Geneva, 1991, p. 804 (Mexico, converted from pesos) and p. 805 (United States).

2 'Mexican Trade Disputed', by John Lippert, Detroit Free Press, March 1, 1991, p. 8B

3 'The Two Valleys of the Green Giant', by Katherine Ellison, San Jose Mercury News, June 16 1991, pages not numbered in the manuscript.

4 'U.S. Corporations' Maquiladora Operations', Social Issue Service Report prepared by the Investor Responsibility Research Center, Inc., Washington, February 8 1991, p. H4

5 Ibid, p. H2.

6 Ibid, p. H7.

7 Ibid, p. H9.

8 'Mexican Maquiladoras: Polluting the Border?', by Michael Satchell, U.S. News and World Report, May 6 1991, p. 36

9 Mill, J.S., Utilitarianism, P. Osker (ed.), New York: Macmillan, 1957.

10 Rawls, J.S., $A$ theory of Justice, Cambridge: Harvard University Press, 1971.

11 Nozick, R. Anarchy, State, and Utopia, New York: Basic Books, 1974. 
12 Posner, R. A., 'Utilitarianism, Economics, and Legal Theory', Journal of Legal Studies, 8, 1979 and D. B. Johnson., 'Wealth is Value', Journal of Legal Studies, 15, 1986.

13 'The Two Valleys of the Green Giant' (Op. Cit.), pages not numbered.

${ }_{14}$ Kant, I., Groundwork of the Metaphysics of Morals, J. Peter (trans.), New York: Harper and Row, 1964.
15 Calabresi, G., 'The Pointlessness of Pareto: Carrying Coase Further', Yale Law Journal, 100, March 1991, pp. 1211-1237.

School of Business Administration, University of Michigan, Ann Arbor, MI 48109,

U.S.A. 